Collection: Cost Action E29 Meeting 2008 - Istanbul (Turkey)

Future Monitoring and Research Needs for Forest Ecosystems

Guest Editor: Marcus Schaub (WSL, Birmensdorf, $\mathrm{CH}$ )

\title{
Clean air policy under the UNECE Convention on long-range transboundary air pollution: how are monitoring results "translated" to policy action
}

\author{
Johannessen T \\ Concerning clean air policy, under the convention on long-range transboundary \\ air pollution, the following themes are discussed: the history of observed ef- \\ fects; the public awareness and concern for the ecosystem health; the current \\ scientific evidence; the development of the critical load concept, and its ap- \\ plication for an effects-based abatement policy.
}

Keywords: Air pollution, Convention LRTAP, Monitoring, Critical loads

\section{History of observed effects}

Effects of air pollutants have been observed for more than a century. Early observations include records of black snow in Southern Norway in 1881. In the following decades several observations of fish kills and discoloured snow were related to possible transport of air masses from England. In the period 1960-1980, severe fish kills were observed in rivers and lakes in parts of Scandinavia. Also observations of forest dieback in Central Europe caused by sulphur dioxide, and discolouration of forest stands in Schwarzwald (Germany) caused concerns.

\section{Public awareness and concern for the ecosystem health}

A common feature of the observations was their severe effects and the widespread geographical coverage. The same effects and damages were observed in several countries in Europe and in North America. These observations attracted the public attention, and the fear of severe and long-lasting damages

Norwegian Pollution Control Authority Dept., P.O. Box 8100, 0032 Oslo, Norway

\section{@, Tor Johannessen}

(tor.johannessen@sft.no)

Received: Jul 19, 2008 - Accepted: Dec 09, 2008

Citation: Johannessen T, 2009. Clean air policy under the UNECE Convention on longrange transboundary air pollution: how are monitoring results "translated" to policy action. iForest 2: 49-50 [online: 2009-01-29] URL: http://www.sisef.it/iforest/show.php? id $=476$ to natural ecosystems made it a policy issue. Awareness that something seemed to happen to the forests and freshwater ecosystems was growing, and the public and political awareness and concern of environmental issues in general was growing.

\section{Scientific evidence is emerging}

At the same time, the scientific evidence was strengthened and underpinned what was happening. In the 1970's, the results of an OECD programme confirmed that pollutants emitted to the air were transported across national borders and that they could travel with the air masses over long distances.

National and multilateral research programmes were set up in several European countries and in North America in order to investigate whether the observed effects were caused by "acid rain" or if there were other reasons behind. The hypothesis of "acid rain", leading to deterioration of ecosystems, was in general commonly accepted. The scientific evidence for transport of air pollutants leading to severe effects on ecosystems in regions remote from the emission sources led European policy-makers to establish an international platform to abate air pollution in Europe; the Convention on Long-range Transboundary Air Pollution, with the United Nations Economic Commission for Europe (UNECE) serving as secretariat. The Convention was adopted and signed by 32 Parties in Geneva on 13 November 1979, and it entered into force 16 March 1983. The Convention has now 51 Parties, including most European countries, the EU, Canada and USA.

The Convention's Working Group on Ef- fects (WGE) was set up in 1981 and laid the basis for the cooperative monitoring and research programmes. The effect-oriented programmes now comprise six International Cooperative Programmes (ICPs) on monitoring air pollution effects on different compartments of the environment, on crops and materials. There is also established a Task Force on Health Aspects (TFH) in collaboration with the World Health Organization (WHO), addressing health effects of air pollutants.

There are now seven protocols which aim at reducing the emissions of sulphur dioxide, nitrogen oxides, ammonia, volatile organic carbon, heavy metals and persistent organic pollutants in Europe. Five of these protocols are "technology-based", i.e., that all Parties to the respective protocols have the same obligations to reduce emissions, and the abatement measures are based on well-known technology.

\section{Development of the critical load concept, and its application for an effects-based abatement policy}

In 1988, the idea of establishing scientifically based tolerable limits of air pollutants for ecosystems was introduced to the science and policy communities. Numerous workshops were addressing the scientific basis for setting critical loads for surface waters and forest soils for acidification, nutrient nitrogen and heavy metals. Similarly, critical levels for air pollutants for forests and other vegetation were addressed. The possible policy application of critical load and level concept was also developed. The broad participation from a European-wide science community in developing the critical loads/levels has led to a common acceptance of the scientific results and on the use for further abatement policies.

Parallel with the development of the critical load concept, the integrated assessment modelling was developed as a tool for a costeffective emission reduction with the aim of ecosystem mitigation. Integrated assessment modelling brings together the scientific knowledge on emissions and transport of air pollutants, effect of air pollutants including critical loads/levels and their exceedances and emission reduction costs.

The Executive Body (EB) of the Convention decided that the negotiations on further reductions of emissions of sulphur dioxides in Europe should be effects-based, building on the critical load/level concept. The second sulphur protocol is probably the first international agreement which has an effects-based approach. EB decided that the further reductions of the "traditional" air pollutants and their effects should be based on the critical load/levels principles. The Gothenburg Pro- 


\section{Definitions of critical load and critical levels}

- "Critical load": a quantitative estimate of an exposure to one or more pollutants below which significant harmful effects on specified sensitive elements of the environment do not occur, according to present knowledge;

- "Critical levels": the concentration of pollutants in the atmosphere above which direct adverse effects on receptors, such as human beings, plants, ecosystems or materials, may occur, according to present knowledge.

tocol ("Multi pollutant - multi effect") was adopted and signed by 31 Parties to the Convention in 1999 and it entered into force on 17 May 2005. The Gothenburg Protocol was reviewed in 2007, and the conclusions were that the emission reductions achieved have been substantial. This has led to the first signs of chemical and biological recovery (e.g., ECE/EB.AIR/WG.1/2007/7)

However, severe effects of air pollutants are still observed and the critical loads for acidity and nutrient nitrogen are exceeded in large parts of Europe. With the current legislation, (i.e., the national regulations on air emissions in year 2010), seven percent of the Convention area is still at risk in 2010 with respect to acidity. The area at risk due to nutrient nitrogen is 48 percent in 2010 . Ground level ozone causes widespread damage to crops and (semi-)natural vegetation in particular in Central and Southern Europe. Ozone also poses a threat to human health in Europe. Particulate matter (PM) is associated with 348000 premature deaths in Europe (ECE/EB.AIR/WG.1/2007/14/Rev.1). In addition, PM has a negative impact on materials.

\section{Challenges for the future work on effects-based policy}

Based on the Gothenburg Protocol review, the EB has mandated the Working Group on Strategies and Review (WGSR) to commence, in 2008, negotiations on further obligations to reduce emissions (ECE/EB.AIR/ 91). In doing this, the EB has decided that, "building upon the achievements of the Gothenburg Protocol, any revision or new protocol should consider setting new environmental targets for the current decade or longer (e.g., 2020) with the aim of ensuring further progress" (ECE/EB.AIR/91). The EB encouraged and invited the WGE to increase its work on quantifying policy-relevant effects indicators, in particular for biodiversity. These indicators should also be linked to the integrated assessment modelling activities

The challenge to the effects oriented communities is to contribute to identify these possible environmental targets. The advice from WGE is to use the most recent scientific results on critical loads and levels for the revision of the Gothenburg Protocol. Another priority task for the ICPs is to identify good indicators which can be used for policy relevant indicators

The WGE has discussed these challenges with a view to meet the request from the Executive Body. This work is partly covered by the work-plan items common to all ICPs and the TFH comprising among others:

1. review of the Gothenburg Protocol, which was delivered in 2007 to the WGE, the WGSR and the EB;

2. dose-response relationships and stock-atrisk;

3. links between observations and critical load/levels exceedances, and;

4. robustness of results.

The items (2) and (3) were reported to the WGE in 2008.

The WGE will continue the efforts on streamlining of the activities of the ICPs and TFH. This streamlining allows for making joint assessments of effects of air pollutants by making use of all the monitored and modelled results from all the effects oriented activities. It is important to keep up the monitoring and modelling activities and to strengthen the reporting of the results. Effects data are essential to assess the effectiveness and sufficiency of abatement measures. Long time series of environmental data are becoming increasingly more valuable with time. Long time series are a prerequisite for elaborating time trends, they provide basis for further research on dose-response relationships, and they are essential to develop the understanding of the processes and dynamics of effects of air pollutants in the environment.

\section{Regulations Cited}

- Convention on Long-range Transboundary Air Pollution:

http://www.unece.org/env/lrtap/welcome.html

- The Executive Body (EB) of the Convention: http://www.unece.org/env/lrtap/ExecutiveBureau/welcome.html

- ECE/EB.AIR/91:

http://www.unece.org/env/lrtap/ExecutiveBureau/welcome.25.html

- The Working Group on Effects (WGE): http://www.unece.org/env/lrtap/WorkingGroups/wge/welcome.html

- ECE/EB.AIR/WG.1/2007/7: http://www.unece.org/env/lrtap/WorkingGroups/wge/26meeting.htm

- ECE/EB.AIR/WG.1/2007/14/Rev.1: http:// www.unece.org/env/lrtap/WorkingGroups/ wge/26meeting.htm

- Protocols under the Convention LRTAP: http://www.unece.org/env/lrtap/status/lrtap s.htm

- Protocol to the 1979 Convention on Longrange Transboundary Air Pollution on further Reduction of Sulphur Emissions, Geneva 1994.

- The 1999 Gothenburg Protocol to Abate Acidification, Eutrophication and Groundlevel Ozone, Geneva 1999. 